\title{
Optimizing the preparation conditions and characterization of a stable and recyclable cross-linked enzyme aggregate (CLEA)-protease
}

\author{
Safa Senan Mahmod*, Faridah Yusof, Mohamed Saedi Jami and Soofia Khanahmadi
}

\begin{abstract}
Background: Cross-linked enzyme aggregate (CLEA) is considered as an effective technique in the production of immobilized biocatalysts for its industrially attractive advantages. Simplicity, stability, low cost, time saving and reusability are proved to be some of CLEA's main advantages.

Results: In this study, an active, stable and recyclable CLEA-protease from the viscera of channel catfish Ictalurus punctatus has been prepared. Optimization of the preparation parameters is carried out with the help of Response Surface Methodology. This methodology helped in studying the interaction between the most contributing factors such as cross-linker, precipitant and the additive concentrations. The optimum specific activity for CLEA-protease of $4.512 \mathrm{U} / \mathrm{mg}$ protein has shown a high stability against the denaturation forces such as temperature and $\mathrm{pH}$ as compared to free protease. It is further found from the study that the highest activity was achieved at the pH of 6.8 and at the temperature of $45^{\circ} \mathrm{C}$. After six cycles, CLEA-protease maintained $28 \%$ of its original activity. Additionally, Michaelis-Menten models were used to determine the kinetic parameters i.e. $K_{m}$ and $V_{\max }$ that helped in showing a significant difference after immobilization as compared to free protease.
\end{abstract}

Conclusion: This work found that this novel CLEA-protease can be used as a very active biocatalyst in industrial applications.

Keywords: Cross-linked enzyme aggregate, Enzyme specific activity, Fish viscera, Michaelis-Menten kinetics, Protease, Response Surface Methodology

\section{Background}

Recently, an increased demand for hydrolytic enzymes has been witnessed, especially for proteases due to its numerous applications in different industrial areas, such as the food, leather and detergent industries ( $\mathrm{Li}$ et al. 2009). It has been reported that protease occupies about $60 \%$ of the hydrolases in the industrial market. Furthermore, it also accounts for almost quarter of the enzyme's overall global production (Gupta et al. 2009). Proteases of different sources for hydrolysis of proteins for commercial uses appear to be extremely helpful because of the enzyme's biological origins (Capiralla et al. 2002). In the meantime, most of the available studies regarding

${ }^{*}$ Correspondence: safa89sinan@hotmail.com

Department of Biotechnology Engineering, International Islamic

University Malaysia, P.O. Box 10, Gomabak, 50728 Kuala Lumpur, Malaysia proteases production have been obtained from microbial origin (Soares et al. 2005; Tang et al. 2004). In an earlier study, conducted by Mahmod et al. (2014), it was found that visceral protease extracted from channel catfish (Ictalurus punctatus) has proven to be highly active. It is further revealed that the use of visceral protease, which is extracted from channel catfish, has several advantages such as making use of this wasteful by-product to produce potential biocatalyst with high activity. Additionally, it is considered as a free and available rich source of enzymes (Mahmod et al. 2014).

In order to protect the enzymes from harsh conditions and to conserve its functional stability, immobilization technique is used in the industrial applications. This leading technique promotes several beneficial features of the enzyme such as offering greater stability and activity, resistance to inhibition,

\section{黛 Springer}

(c) 2016 Mahmod et al. This article is distributed under the terms of the Creative Commons Attribution 4.0 International License (http://creativecommons.org/licenses/by/4.0/), which permits unrestricted use, distribution, and reproduction in any medium, provided you give appropriate credit to the original author(s) and the source, provide a link to the Creative Commons license, and indicate if changes were made. 
selectivity or specificity, higher performance of catalysts, and reusability (Torabizadeh et al. 2014). Enzyme immobilization is proven to be one of the key steps in making the enzymatic processes economically practicable (Cao and Schmid 2005; Zhou 2009). According to the study of Parmar et al. (2000), it is also found that the immobilized enzyme catalyst with the improved activity and stability can reduce the production cost. Cross-linking enzyme aggregate (CLEA) is described as the latest enzyme immobilization technology (Barbosa et al. 2014; Brady and Jordaan 2009; Sheldon et al. 2005).

CLEA's preparation is considered as a very simple procedure that involves enzyme's precipitation, which does not need to be purified. However, physical precipitation of the enzymes' molecules into super-molecular structures can take place through the addition of organic solvents, non-ionic polymers or salts to protein sample's aqueous solution (Sheldon 2007). The study has further highlighted the fact that CLEAs are produced with the help of physical cross-linking of protein aggregates. CLEA's activity is maintained; since it is considered as a restructured superstructure of the aggregates (Kartal et al. 2011). Hence, in order to stabilize these aggregates, the step of crosslinking appears to be necessary for the process so that the enzymes cannot be re-dissolved during the removal of precipitants. In previous researches, protease was successfully immobilized using CLEA technology (Skovgaard et al. 2010; Sangeetha and Abraham 2008).

In this study, protease extracted from the viscera of channel catfish (Ictalurus punctatus) was immobilized using cross-linked enzyme aggregates technique in acetone as an organic medium. The type of the suitable additive was studied and the optimum preparation conditions of CLEA-protease preparation were investigated using Response Surface Methodology (RSM). The resulted CLEA-protease was illustrated in terms of optimum $\mathrm{pH}$ and optimum temperature as well as thermal stability and $\mathrm{pH}$ stability. The produced CLEA-protease was also tested for its reusability. Finally, kinetics parameters $\left(V_{\max }\right.$ and $K_{\mathrm{m}}$ ) were determined using Michaelis-Menten models.

$$
\text { Enzyme activity }(\mathrm{U} / \mathrm{mL})=\frac{(\mu \text { mole of tyrosine released }) \times \text { Total volume of assay }(\mathrm{mL})}{\text { Volume of used enzyme }(\mathrm{mL}) \times \text { Time of assay } \times \text { Volume in cuvette }(\mathrm{mL})}
$$

(Germany) has been used for agitation during the preparation of CLEA-protease.

\section{Protease sample preparation}

Channel catfish's viscera was obtained from a local market in Selangor/Malaysia, and was washed and weighed (749 g) before mixing with $1 \mathrm{M}$ phosphate buffer ( $\mathrm{pH} 7.3$ ) in the blender with a ratio of 2:1 buffer-to-viscera, then sample was filtered using a muslin cloth.

Filtrate was then centrifuged for $1 \mathrm{~h}$ at $4{ }^{\circ} \mathrm{C}$ and $12,000 \mathrm{rpm}$; the supernatant collected was used to prepare the crude enzyme by precipitating for $24 \mathrm{~h}$ at $4{ }^{\circ} \mathrm{C}$ with $4 \mathrm{M}$ ammonium sulphate with continuous stirring. Next, the sample was dissolved in PBS and centrifuged at $3000 \mathrm{rpm}$ for $15 \mathrm{~min}$ at $4{ }^{\circ} \mathrm{C}$. This was followed by dialysis against minimal phosphate buffer saline $\mathrm{pH} 7$ by $(10000$ MWCO) and left for $4 \mathrm{~h}$ with continuous mixing at $4{ }^{\circ} \mathrm{C}$. Afterwards, the sample was stored at the temperature of $-20{ }^{\circ} \mathrm{C}$ for additional tests.

\section{Protein concentration}

Bradford assay using BSA as standard has also been deployed for measuring the protein content present in the prepared sample (Bradford 1976).

\section{Protease activity assay}

The enzymatic activity of protease was determined using the modified universal procedure described by Sigma-Aldrich with casein as a substrate (SigmaAldrich 2013). The substrate solution was prepared by dissolving $1 \mathrm{~g}$ of casein in $100 \mathrm{~mL}$ of $50 \mathrm{mM}$ Tris$\mathrm{HCl}$ buffer, $\mathrm{pH}$ 8. Afterwards, $1 \mathrm{~mL}$ of enzyme solution was added to the substrate solution and incubated for $20 \mathrm{~min}$ at the temperature of $35{ }^{\circ} \mathrm{C}$. As a reaction terminator, $4 \mathrm{~mL}$ of $10 \%$ trichloroacetic acid (TCA) was used. Measurement of absorbance was taken at $660 \mathrm{~nm}$ and preparation of tyrosine standard curve was also carried out. The equation below was used to measure the enzyme activity (Sigma-Aldrich 2013) with modification:

\section{Methods \\ Materials}

All of the chemicals used in this study are of analytical grades with different brands (Merck, Sigma-Aldrich, System and Bio-Rad) and are obtained from the local supplier Essen Haus Sdn. Bhd and Merck Sdn. Bhd. In order to measure the absorbance, Tecan micropalte reader (Switzerland) is used. Furthermore, Sartorius Shaker 


$$
\text { Recovered activity }(\%)=\frac{\text { Activity of CLEA }- \text { protease }}{\text { Activity of free enzyme used for CLEA }- \text { protease preparation }} \times 100 \%
$$

\section{Selection of additives}

In this study, three additives were studied for their effects on the activity of CLEA-protease; they are $50 \mathrm{mg}, 10 \mathrm{mg}$, $50 \%(\mathrm{v} / \mathrm{v})$ of bovine serum albumin (BSA), sodium dodecyl sulphate (SDS) and heptane, respectively. The precipitant and the cross-linker values were fixed based on a previous study (Yusof et al. 2013) at acetone $=60 \%(\mathrm{v} / \mathrm{v})$ and glutaraldehyde $=60 \mathrm{mM}$.

Immobilization mixture was prepared in triplicates. It consisted of $1 \mathrm{~mL}$ of enzyme solution, precipitant, glutaraldehyde and an additive. The samples were shaken at $200 \mathrm{rpm}$ in the shaker for $17 \mathrm{~h}$ at room temperature. Samples were collected and centrifuged at $6000 \mathrm{rpm}$ at the temperature of $4{ }^{\circ} \mathrm{C}$ for $30 \mathrm{~min}$, and washed three times with $3 \mathrm{~mL}$ of acetone. The process was then followed by determination of the protease activity by conducting the standard assay (in "Protease activity assay").

\section{Optimization of CLEA-protease preparation conditions}

The optimization of the preparation parameters of CLEAs is reported to be an extremely complicated process (Cruz et al. 2012). Any parameter that may change the aggregation or the aggregate cross-linking will possibly have an effect on the recovered activity and particle size. Likewise, the co-interaction among these three main factors (cross-linker, precipitant and additive) in many cases can affect CLEAs final form (Yu et al. 2006).

In this experiment, the optimization of the preparation parameters was carried out with the help of Response Surface Methodology. In fact, RSM can locate any minimum or maximum response that exists inside the factor region. In order to fit a quadratic function, three different values for each factor are essential for this purpose. Among the commonly used response, surface design in statistical analysis is the central composite design which combines a two-level fractional factorial, centre points and axial points (JMP 2005).

The crude sample $(1 \mathrm{~mL})$ was aggregated by adding acetone in various concentrations [30, 45, $60 \%(\mathrm{v} / \mathrm{v})]$, then cross-linked by the addition of glutaraldehyde (50, $65,80 \mathrm{mM})$ and $(0.038,0.113,0.188 \mathrm{mM})$ of BSA that was added at the end as an additive. As a result of which, the total volume of the solution was found to be $4 \mathrm{~mL}$. After $17 \mathrm{~h}$ of incubation, the CLEA-protease was separated from the supernatant by centrifuging at $6000 \mathrm{rpm}$ at $4{ }^{\circ} \mathrm{C}$ for $20 \mathrm{~min}$. In order to take out the excess amount of glutaraldehyde, the sample was washed three times with $3 \mathrm{~mL}$ of acetone.

\section{Characterization of CLEA-protease PH stability of CLEA-protease}

The effect of $\mathrm{pH}$ on immobilized protease stability was evaluated by incubating CLEA-protease at different $\mathrm{pH}$ values ranging from 4.5 to 9.5 (acetate, phosphate, Tris- $\mathrm{HCl}$, glycine- $\mathrm{NaOH}$ buffers) for $30 \mathrm{~min}$. Supernatants were removed by centrifugation and the activity of the immobilized/free enzyme was determined using the standard protease activity assay. The residual activities for CLEAs and free enzyme were calculated in percentage with reference to the highest $\mathrm{pH}$ value $(=100 \%)$.

\section{Effect of $\mathrm{pH}$ of the activity of CLEA-protease}

The optimum $\mathrm{pH}$ values for the immobilized and free protease were determined using the substrate prepared in buffers of varying $\mathrm{pH}$ values from 4.5 to 9.5 . The relative activity was measured by considering the highest activity to be $(=100 \%)$.

\section{Thermal stability of CLEA-protease}

Free and immobilized enzymes were incubated at different temperature values $\left(25-65{ }^{\circ} \mathrm{C}\right)$ for $30 \mathrm{~min}$. Samples were periodically withdrawn to run the activity assay. The residual activities were determined as above.

\section{Effect of temperature}

In order to determine the optimum temperature of free protease and CLEA-protease, activities were measured in the temperature ranging from 25 to $65^{\circ} \mathrm{C}$. Both forms of enzyme (free and immobilized) were incubated in water bath for $20 \mathrm{~min}$ at different temperatures, after cooling protease activity was assayed in the standard conditions and the absorbance was taken to measure both activities.

\section{Organic solvent stability of CLEA-protease}

After preparing CLEA-protease, CLEAs were stored in acetone at $4{ }^{\circ} \mathrm{C}$ for 4 days and the activity of protease was daily measured to determine the stability of CLEA-protease in acetone. The first day's activity was considered $100 \%$ and the runs were measured in reference to it.

\section{Reusability of CLEA-protease}

The reusability of the produced CLEA-protease was determined by the repeated use of CLEA-protease in substrates hydrolysis for six cycles (2 days per cycle). Between cycles, CLEAs were recovered by centrifugation (at $4000 \mathrm{rpm}$, for $20 \mathrm{~min}$, at $4{ }^{\circ} \mathrm{C}$ ) and washed thrice with $3 \mathrm{~mL}$ of acetone to insure the separation of CLEAs from the reaction mixture. Then CLEA-protease was 
resuspended in a fresh batch of reaction medium for 2 days. The relative activity of CLEA-protease obtained in the first cycle was assigned as $100 \%$.

\section{Kinetic study}

The kinetic study for the hydrolytic activity of substrate was investigated using Michaelis-Menten kinetic models. Hyperbolic Regression Analysis Software (Hyper32) was used, which has been designed on non-linear regression analysis and is more preferable to the common linear method. The kinetic study was carried out by conducting the protease assay for each of free protease and CLEA-protease (noting that same amount of free enzyme was used to prepare CLEA, which is $1 \mathrm{~mL}$ ) using different concentrations of casein $[0.2,0.6,1.0,1.4,2.8,2.2,2.6$, and $3 \%(\mathrm{w} / \mathrm{v})]$, dissolved in $50 \mathrm{mM}$ phosphate buffer solution (pH 7.0) and the incubation time was set to $10 \mathrm{~min}$ at the temperature of $35{ }^{\circ} \mathrm{C}$. The evaluation of the MichaelisMenten was based on Hanes-Woolf, Lineweaver-Burk, Eadie-Hofstee and hyperbolic regression models.

\section{Results and discussion}

In an earlier study, the specific activity of protease extracted from channel catfish viscera was found to be $13.57 \mathrm{U} / \mathrm{mg}$ proteins (Mahmod et al. 2014). In the current study, CLEA-protease is produced by the precipitation of protease that was carried out by adding acetone as an organic solvent. It has been then followed by crosslinking through the use of bi-functional reagent i.e. glutaraldehyde.

\section{Selection of additives}

Three additives were tested for their effect on the activity of CLEA in organic solvent medium, they were selected based on the different effects on CLEAs expected from each. BSA behaves as a feeder (Dong et al. 2010), heptane for interfacial activation (Torres et al. 2013) and SDS as surfactant that facilitates the precipitation and increases interfacial surface of the enzyme (Gupta et al. 2002). The CLEA activity without any additive is considered $100 \%$ relative activity. Figure 1 illustrates the relative activity of CLEA-protease each time with different additives.

Bovine serum albumin showed the highest activity when the BSA-to-protease ratio was 50:1. It is due to the fact that BSA acts as a proteic feeder which helps in facilitating the formation of CLEAs in cases where the protein concentration is too low or if the activity of enzymes appears to be weak when the required glutaraldehyde is at high concentrations to gain the aggregates (Shah et al. 2006; Aytar and Bakir 2008). However, glutaraldehyde reacts with the free amino groups of the amino acids present on the enzyme surface i.e. lysine. Moreover, the improvement in activity after the addition

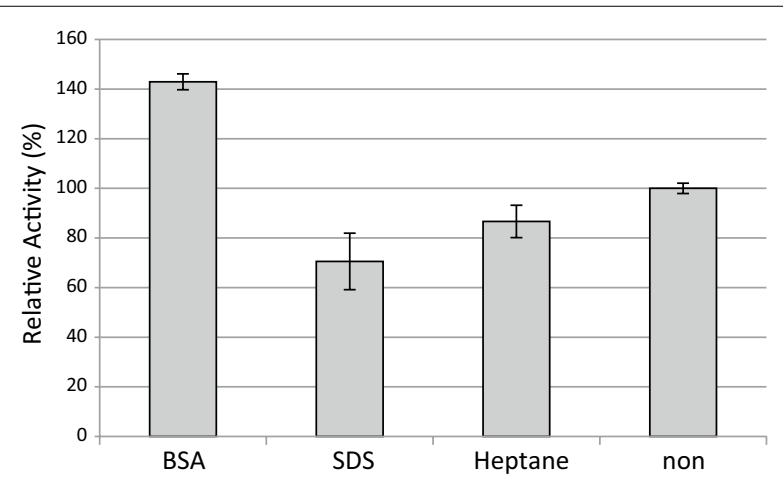

Fig. 1 Effect of different additives on the activity of CLEA-protease, CLEAs without additive (non) is $100 \%$ relative activity

of BSA is explained as that the lysine residues provided by this molecule can bind with glutaraldehyde to prevent the denaturing of the targeted protein. In a similar study, it has been reported that there is a linear relationship between the CLEAs recovered activity and the amount of BSA added (Torres et al. 2013).

On the other hand, the addition of the surfactant SDS has shown lower activity than the native (without additive) CLEA. The interaction between the surfactant and the enzyme is known to be hydrophobic (Maldonado-Valderrama and Patino 2010) that may increase the interfacial surface of the enzyme. But, in this experiment, the precipitant used (acetone) was enough to perform the aggregates. SDS generally binds un-specifically to the protein surface, which usually leads to protein unfolding (Mogensen et al. 2005). On the other hand, Pan et al. (2014) reported that adding a surfactant to the mixture can facilitate the dispersal of the water-insoluble substrate through the formation of micellar system, it can also improve the substrate's mass transfer, leading to an increase in the substrate concentration which can ease the downstream separation effectively and reduce the cost of the product.

Finally, heptane was used to increase the surface activity of the enzyme in CLEAs preparation (Torres et al. 2013). Heptane is one of the non-polar organic solvents that are usually considered to be hydrophobic molecules (like several organic molecules' hydrocarbon backbone). It makes the surrounding water molecules to be in order. In the case of enzyme and substrate reactions, the well organized water molecules are moved away from the area between the two groups for allowing more interfacial interaction. Therefore, the formation of enzymesubstrate complex becomes easier. This in turn, initiates a chain of chemical reactions that are directed by the enzyme (Nelson and Cox 2004). In case of CLEA preparation, the relative activity obtained with the addition of heptane was slightly less than that of CLEA's without 
additives. Hence, it indicated that more interfacial surface was provided. However, each enzyme's surface was interacted with other enzymes and substrate as well as the cross-linking agent.

Additionally, in order to statistically analyse the selection process of the additives, one-way ANOVA analysis was carried out. In one-way ANOVA analysis for all the groups ( $p$ value $<0.01) F$ is also less than $F$ critical, meaning that the design is significantly different. However, the detailed one-way ANOVA analysis of t-test has been carried out which assisted in presenting the interaction between each two groups. BSA was significantly different from all the other groups. SDS differs significantly with BSA and no-additive, but there is no significant difference with heptane. Likewise, heptane is significantly different from BSA, but there is no significant difference with the effect of SDS and no-additive groups.

The CLEA-protease activity without any additive was $2.42 \pm 0.401 \mathrm{U} / \mathrm{mg}$, that is much less than the free protease activity $(13.75 \pm 0.380 \mathrm{U} / \mathrm{mg})$, this is because crosslinking provided less active site to be attached with the substrate. After adding BSA to CLEA (specific activity of $3.46 \pm 1.215 \mathrm{U} / \mathrm{mg}$ ), the activity increased by $42.97 \%$, possibly because more amino group was added to the surface of the enzyme. Thus, the additive selected to prepare CLEA-protease was BSA. Previous studies have shown similar findings to this result, whereby $28.7 \%$ recovered activity of CLEA was observed after adding $0.1 \mathrm{mg}$ of BSA (Cabana et al. 2007). In another study (Dong et al. 2010), it was reported that the addition of $10 \mathrm{mg}$ BSA per $100 \mathrm{mg}$ of enzyme has resulted in an increase of recovered activity from 24 to $82 \%$. An increase of activity upon the addition of BSA was also observed by Shah et al. (2006), whereby the prepared CLEA recovered $100 \%$ of its activity (as compared to free enzyme) upon the addition of BSA, compared to $0.4 \%$ without BSA. Moreover, the study of Torres et al. (2013) reported that the addition of BSA as a feeder helped in improving the step of crosslinking and allowed a better stabilization of CLEAs produced, and the recovered activity of CLEAs was found to be $31.3 \%$ when adding $75 \mathrm{mg}$ of BSA.

\section{Optimization of CLEA-protease preparation}

Design Expert 6.0.8 was used for designing the optimization model for this study. Table 1 shows the Faced Centred Central Composite Design of the Response Surface Methodology for optimizing the preparation parameters of CLEA-protease. It was carried out by varying the concentrations of glutaraldehyde, acetone and BSA. The highest recovered CLEA-protease activity determined was found to be $33.25 \%$ in Run 5 , as shown in Table 1 , at $65 \mathrm{mM}, 45 \%(\mathrm{v} / \mathrm{v})$ and $0.113 \mathrm{mM}$ of glutaraldehyde, acetone and BSA, respectively.
According to the analysis of variables (ANOVA), the model was significant and there is only a $0.81 \%$ chance that a "Model $F$ value (that is 7.227)" could take place due to noise, and the mean square of the model was 1.594. The correlation coefficient was 0.91 . In general, the experimental data have shown that this model can be used to navigate the design space.

The statistical Eq. (3) indicates that the positive values have positive effect on the response and the negative values have negative effect on the response, where, $A$ is glutaraldehyde, $B$ is acetone and $C$ is BSA concentrations.

$$
\begin{aligned}
& \text { Recovered activity of CLEA }- \text { protease }(\%) \\
& =+27.83-2.08 A+2.92 B-0.059 C-3.23 A^{2}-4.89 B^{2} \\
& -6.29 C^{2}+0.62 A B-2.19 A C-0.33 B C
\end{aligned}
$$

The effect of each parameter involved in preparation of CLEA-protease is shown in Fig. 2. The concentration of acetone as a precipitant helped in forming the aggregates that is the initial step for cross-linking, too little precipitant is not enough to form the aggregates, while high acetone concentration reduces the protein residues in supernatant indicating that more free protease was precipitating in forming the insoluble enzyme aggregates. Also, high acetone concentration may lead to protein denaturation that is responsible for the activity loss (Wang et al. 2011). The study of Wang et al. (2011) has reported that the drop in the activity of CLEAs is related to the polarity of the organic solvent used for precipitation, where $\log \mathrm{P}$ is known as the ratio of the compound's concentration in the phase of octanol/water ( $\log \mathrm{P}$ for acetone is -0.24 ). The water miscible solvents (i.e. acetone) can strip the protein-bound water that is essential to maintain the structure and function of the enzyme (Serdakowski and Dordick 2008).

The suitable concentration of glutaraldehyde for crosslinking was found to be $65 \mathrm{mM}$. For higher concentrations of glutaraldehyde, the activity observed was low, this can be explained as an excessive cross-linking happened that resulted in losing some of the flexibility of the enzyme which is required for its activity (Yu et al. 2013), or more cross-linking occurred leading to too strong CLEA with a strong diffusion resistance (Dong et al. 2010). Usually, the activity of CLEAs prepared using glutaraldehyde appears to be highly dependent on the type of enzyme as well as the concentration of glutaraldehyde. It is due to the high reactivity of the enzyme and the small size of glutaraldehyde. The activity of CLEAs reduces as compared to the free enzyme form when the catalytical residues of the enzyme react with glutaraldehyde (Kim et al. 2013). Hence, the use of other protein as a "feeder" was proposed to enhance the activity of CLEA 
Table 1 Experimental design for optimization of CLEA-protease preparation parameters, using faced cantered central composite design FCCCD and response surface methodology RSM, all experiments were done in triplicate

\begin{tabular}{lllllc}
\hline Run & $\begin{array}{l}\text { Glutaraldehyde } \\
(\mathbf{m M})\end{array}$ & Acetone $\%(\mathbf{v} / \mathbf{v})$ & BSA (mM) & $\begin{array}{l}\text { Protease specific } \\
\text { activity } \\
\text { (U/mg protein) }\end{array}$ & $\begin{array}{l}\text { CLEA-protease } \\
\text { recovered activity } \\
(\%)^{\mathbf{a}}\end{array}$ \\
\hline 1 & $65.00(0)$ & $60.00(+1)$ & $0.113(0)$ & 3.03 & 22.04 \\
2 & $80.00(+1)$ & $60.00(+1)$ & $0.188(+1)$ & 1.61 & 11.71 \\
3 & $50.00(-1)$ & $60.00(+1)$ & $0.188(+1)$ & 3.01 & 21.89 \\
4 & $65.00(0)$ & $30.00(-1)$ & $0.113(0)$ & 2.85 & 20.73 \\
5 & $65.00(0)$ & $45.00(0)$ & $0.113(0)$ & 4.57 & 33.24 \\
6 & $50.00(-1)$ & $45.00(0)$ & $0.113(0)$ & 3.43 & 24.95 \\
7 & $80.00(+1)$ & $30.00(-1)$ & $0.188(+1)$ & 0.96 & 6.98 \\
8 & $65.00(0)$ & $45.00(0)$ & $0.113(0)$ & 3.63 & 26.40 \\
9 & $80.00(+1)$ & $30.00(-1)$ & $0.038(-1)$ & 1.13 & 8.22 \\
10 & $65.00(0)$ & $45.00(0)$ & $0.113(0)$ & 4.14 & 30.11 \\
11 & $80.00(+1)$ & $45.00(0)$ & $0.113(0)$ & 2.91 & 21.16 \\
12 & $50.00(-1)$ & $60.00(+1)$ & $0.038(-1)$ & 2.16 & 15.71 \\
13 & $50.00(-1)$ & $30.00(-1)$ & $0.188(+1)$ & 1.93 & 14.04 \\
14 & $50.00(-1)$ & $30.00(-1)$ & $0.038(-1)$ & 1.67 & 12.15 \\
15 & $80.00(+1)$ & $60.00(+1)$ & $0.038(-1)$ & 2.73 & 19.85 \\
16 & $65.00(0)$ & $45.00(0)$ & $0.188(+1)$ & 2.79 & 20.29 \\
17 & $65.00(0)$ & $45.00(0)$ & $0.038(-1)$ & 2.70 & 19.64 \\
\hline
\end{tabular}

a Recovered activity (\%) was calculated according to Eq. 2

by increasing the amount of amino residues (GarciaGalan et al. 2011), such as BSA.

In Fig. $2 b$ and $c$, with the increase of BSA concentration, the enzyme molecule is tightly attached to it, which effectively lowers the effect of the precipitant. However, the enzyme will not be attached to all of the BSA molecules in the presence of excess amount of BSA; hence enzyme aggregates will be formed. Nonetheless, the addition of BSA as a co-feeder allowed the cross-linking step to act effectively, and lead to better stabilization of the CLEA-protease produced (Torres et al. 2013).

There are many studies indicated that RSM and FCCCD are the best methods which are used to optimize the preparation of CLEAs. For example, according to Khanahmadi et al. (2015), CLEA-lipase activity was increased by 2.5-fold after optimization using response surface methodology and faced central composite design (FCCD) as compared to the activity obtained in One-Factor-at-aTime method. In another study, the preparation of hybrid magnetic cross-linked enzyme aggregates had been successfully optimized using centered composite design (CCD), it helped in explaining the interaction relationship among the main preparation factors to obtain recovery activity of $43.27 \%$ (Cui et al. 2014). Similarly, the preparation of CLEA-naringinase was optimized with the help of Response Surface Methodology and Central Composite Rotatable Design (CCRD) (Ribeiro and Rabaça 2011). Response Surface Methodology has been implemented for optimizing the preparation of CLEA- hydroxynitrile lyase purified from seeds of Prunus dulcis (Yildirim et al. 2014).

\section{Characterization of CLEA-protease \\ Effect of $\mathrm{pH}$ and $\mathrm{pH}$ stability of CLEA-protease}

$\mathrm{pH}$ is one of the most influential parameters altering enzyme activity in an organic medium. The catalytic activity of the immobilized protease in the hydrolysis of the substrate was investigated at different $\mathrm{pH}$ values (4.5-9.5). As shown in Fig. 3a, the optimum pH of the immobilized and free protease was found to be 6.8 and 8.0, respectively. This agrees with previous studies, whereby Hormigo et al. (2012) found out that the optimal CLEA activity was obtained at $\mathrm{pH}$ value of 7.0, which is shifted as compared to its soluble free enzyme's pH that was 8.0. The study of $\mathrm{Xu}$ et al. (2013) has reported that both enzyme forms (free and immobilized) were similarly stable at $\mathrm{pH} \leq 6.0$, and both had maximum value at $\mathrm{pH}$ 6.0. In other words, the immobilization of protease led the optimum $\mathrm{pH}$ curve to shift towards neutral $\mathrm{pH}$ value. According to the research of Hormigo et al. (2012), it was revealed that when the structure of CLEA is enclosed by molecules of BSA protein the $\mathrm{pH}$ in the enzyme's active site microenvironment is shifted towards more alkaline values.

The free protease characterized in this experiment was found to be active functionally in the $\mathrm{pH}$ range of 6.8-8.0; while, the immobilized protease had a wider $\mathrm{pH}$ range, as depicted in Fig. 3b. This indicates its potential 

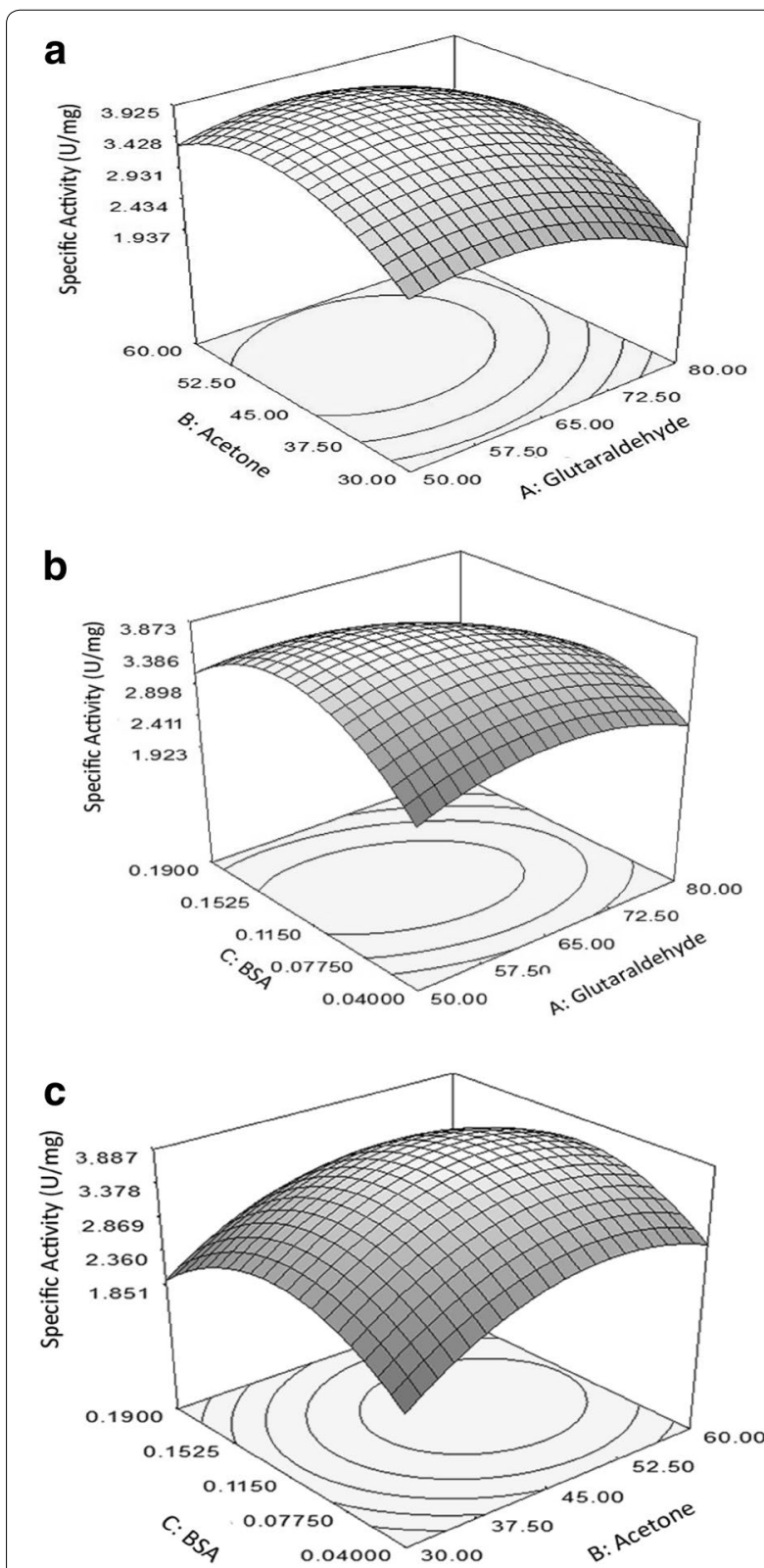

Fig. 2 Response surface plot as a function of CLEA-protease specific activity showing the interaction of $\mathbf{a}$ glutaraldehyde and acetone at constant BSA concentration of $0.12 ; \mathbf{b}$ glutaraldehyde and BSA at constant acetone concentration of $45 \%(\mathrm{v} / \mathrm{v}) \mathbf{c}$ acetone and BSA, as constant glutaraldehyde concentration of $65 \mathrm{mM}$

applicability in several applications, since CLEAs can resist the harsh changes in the environment. It must be taken under consideration that the highest activity of CLEA-protease is achieved at around neutral $\mathrm{pH}$ value.

\section{Effect of temperature on thermal stability of CLEA-protease}

The resistance of the immobilized enzyme to temperature changes is considered as a significant and a major advantage in the practical applications of enzymes. Moreover, the temperature dependence of the relative activity of immobilized and free enzymes was examined for the intervals of $25-65{ }^{\circ} \mathrm{C}$. The results of these experiments are shown in Fig. 3c. It has been observed that the optimal temperature identified for the free as well as immobilized protease was found to be around $45{ }^{\circ} \mathrm{C}$. A drop in the activity of free enzyme was observed at temperatures higher than $45^{\circ} \mathrm{C}$; while, CLEA-protease resisted the increment in temperature and recorded higher activity. Hence, the free enzymes can easily undergo denaturation at higher temperature while immobilized enzymes are protected, probably by its rigid conformation. Thus, immobilized enzymes appear to be capable of retaining their catalytic activity (Tutar et al. 2009).

It has been revealed that one of the major and primary reasons of enzyme immobilization is the anticipated increase in its stability towards various deactivating conditions; it takes place because of the limited conformational mobility of such molecules that follows the immobilization. Resistance of immobilized enzymes towards temperature at some specific time is considered as a significant and major advantage for the enzyme's potential applications. It has been further found that the thermal stability of immobilized protease has also been enhanced significantly. The residual activity of protease was about $20 \%$ for the free enzyme and $60 \%$ for immobilized protease after $2 \mathrm{~h}$ of temperature exposure, as shown in Fig. 3d. The study of Xu et al. (2013) stated that CLEAs were found to be more thermally stable as compared to the free enzymes, as a result of the rigid structure which has been created by the step of cross-linking. Moreover, Kim et al. (2013) reported that CLEAs have shown four times higher thermal stability as compared to that of free enzyme. Such an increment was because of the inter-molecular as well as intra-molecular covalent cross-links which stop the conformational change in CLEAs (Zhu et al. 2001).

\section{Scanning electron microscopy (SEM)}

As it has been reported that the particle shape and size of CLEA are still unexplored (Singh et al. 2013), Skovgaard et al. (2004) has reported two types of CLEAs' structure that can appear under SEM; either a spherical appearance (Type 1) or a less-structured form (Type 2 ), whereby (Type 1) aggregate forms typical balls, and (Type 2) aggregate clusters into less-defined structures. In this study, CLEA-protease from channel catfish viscera is considered as Type 2 (data not shown).

\section{Organic solvent stability of CLEA-protease}

CLEA-protease was stored in acetone in order to maintain its environment and to avoid drastic changes in its 


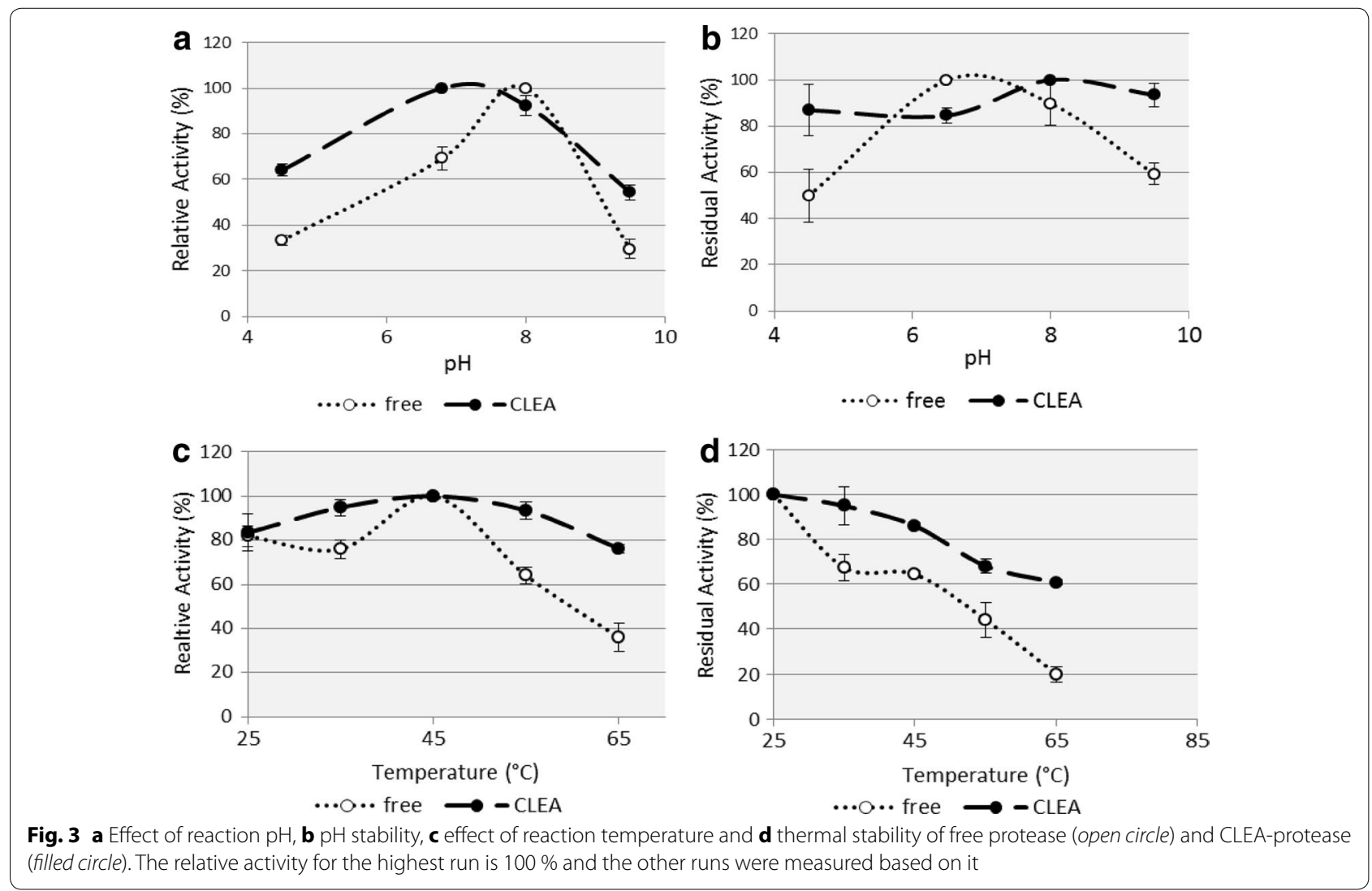

structure that might occur in different environments. Figure 4 shows that the relative activities of CLEA stored in acetone for 4 days were 100, 86, 85 and $70 \%$.

The solvent stability of CLEA is important to be determined since many studies have reported some limitations of using organic solvent with CLEA (Yu et al. 2006; Kartal et al. 2011). Polar solvents (i.e. acetone) can interact with the enzyme as well as the associated water molecules, hence, cause drastic reduction in the catalytic activity (Singh et al. 2013). However, Singh et al. (2013)

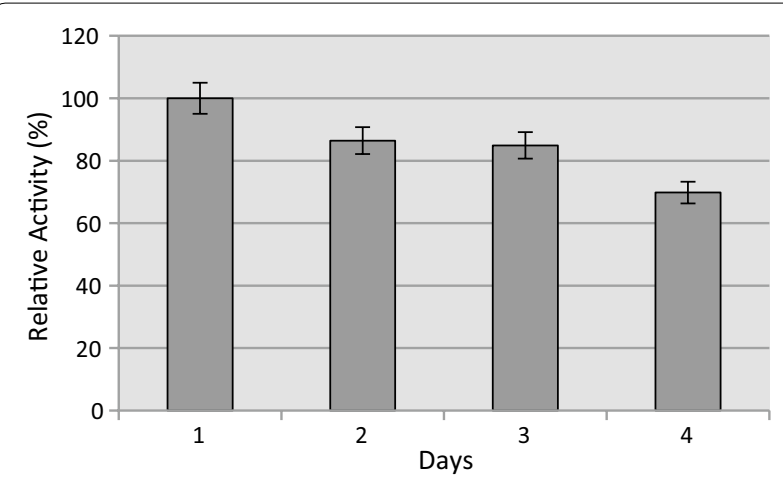

Fig. 4 Organic solvent stability of CLEA-protease mentioned several potential advantages in using nonaqueous solvents, such as enhancement in the solubility of substrates (for instance lipids and phospholipids), novel chemistry in synthetic applications, altered substrate specificity, easy product recovery and reduction in microbial contamination. To further improve the organic stability of the enzyme, Kartal et al. (2011) suggested the mixing of acetone with another buffer.

\section{Reusability test}

One of the most important aims of enzymes immobilization is its reusability that provides opportunities for multiple uses for the same biocatalyst (Torabizadeh et al. 2014). CLEAs have a very promising result in this field, since it can be simply detached from the reaction mixture, washed and reused. Moreover, CLEAs are insoluble in the reaction medium, thus it avoids the product contamination, which is feasible for separation and facilitates the downstream process (Pan et al. 2014). It appears as an essential and significant requirement for their applications in industrial processes.

Results of recycling experiments are shown in Fig. 5, where three runs of the highest activities of CLEA-protease from Table 1 were selected for the reusability test. After each cycle, CLEAs were washed with acetone and 


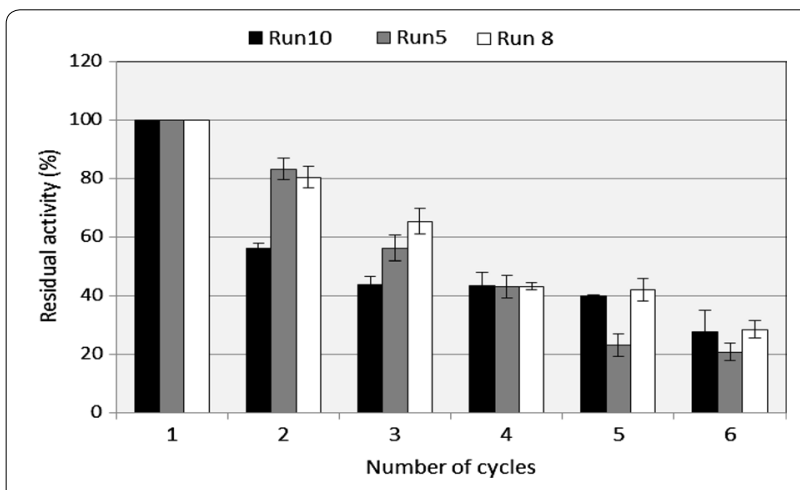

Fig. 5 Recyclability of CLEA-protease
Table 2 Summary of Michaelis-Menten expression for hydrolysis of protease (free and CLEA)

\begin{tabular}{lllll}
\hline Enzyme & Model & $\boldsymbol{R}^{\mathbf{2}}$ & $\boldsymbol{K}_{\mathbf{m}}$ & $\boldsymbol{V}_{\mathbf{m a x}}$ \\
\hline Free protease & Hanes-Woolf & 0.997 & 0.124 & 0.1173 \\
& Lineweaver-Burk & 0.966 & 0.119 & 0.1164 \\
& Eadie-Hofstee & 0.937 & 0.121 & 0.1169 \\
& Hyperbolic regression & 0.930 & 0.127 & 0.1175 \\
CLEA-protease & Hanes-Woolf & 0.993 & 0.258 & 0.514 \\
& Lineweaver-Burk & 0.982 & 0.405 & 0.577 \\
& Eadie-Hofstee & 0.871 & 0.339 & 0.547 \\
& Hyperbolic regression & 0.963 & 0.360 & 0.550 \\
\hline
\end{tabular}

for free protease described the effective substrate hydrolysis perfectly.

On the other hand, the kinetic parameters obtained for CLEA-protease, were extremely different from the results obtained by using free protease. For the four models, $V_{\max }$ increased in CLEAs as compared to free protease values. The coefficient of determination $\left(R^{2}\right)$ was also found to be the highest in Hanes-Woolf model, as indicated in Table 2.

Hence, it can be said that the kinetic parameters of CLEA-protease and free protease were determined by measuring initial reaction rates for each by varying amounts of casein. It was observed that $K_{\mathrm{m}}$ value of CLEA-protease was slightly higher than $K_{\mathrm{m}}$ before immobilization, and $V_{\max }$ values increased after immobilization as compared to free protease. The results indicated that due to the substrate diffusion resistance the cross-linking immobilization has lowered the accessibility of substrate to the immobilized enzyme's active site, which had decreased the affinity of protease. It is also to be noticed, as mentioned earlier, that the optimum $\mathrm{pH}$ for CLEAprotease and free protease were 6.8 and 8 , respectively, this had an effect on the different performances of the two forms of enzyme. Nevertheless, these findings could be linked to the behaviour of the two enzymes (CLEA and free) in any application at neutral $\mathrm{pH}$.

Similar findings were reported about the increased $K_{\mathrm{m}}$ of enzymes after immobilization (Rehman et al. 2013; Lei and Bi 2007). Also CLEA structure has less interfacial interaction with the substrate due to cross-linking as compared to the liquid-form free enzyme. $V_{\max }$ value basically measures how fast the enzyme can hydrolyze a completely saturated substrate; hence an increase in $V_{\max }$ after immobilization means that less substrate is needed to be converted to a product per unit of a time. The catalytic efficiency which is denoted by $V_{\max } / K_{\mathrm{m}}$ of immobilized protease was higher than the catalytic efficiency of plot. This is a good indication that the Michaelis-Menten 
free enzymes (1.992 vs. $\left.0.946 \mathrm{~min}^{-1}\right)$; this is in agreement with Yu et al. (2013).

\section{Conclusion}

For the first time, protease extracted from the viscera of channel catfish (Ictalurus punctatus) was successfully immobilized by CLEA technique. The effect of each of the factors involved in the CLEA-protease production was discussed. In addition, the impact of different additives on the CLEA-protease's activity was also selected and analysed. It has been found that the bovine serum albumin had the maximum effect on CLEA-protease as compared to sodium dodecyl sulphate and heptane. Nevertheless, the addition of BSA as a feeder supported the CLEA mechanically and increased its activity. Experimental design and statistical analysis were used to verify the optimization model. The optimal CLEA-protease recovered activity obtained was $33.24 \%$ in $65 \mathrm{mM}, 45 \%$ $(\mathrm{v} / \mathrm{v})$ and $0.113 \mathrm{mM}$ of glutaraldehyde, acetone and BSA, respectively. Moreover, produced CLEA-protease maintained more than $28 \%$ of its activity after six cycles. Finally, Hanes-Woolf model was the best fit model for determining the kinetic parameters of the hydrolysis reaction. Overall, the results shown in this study propose that CLEA-protease can be a promising tool in increasing the stability and reusability of protease in biotechnological applications.

\section{Authors' contributions}

SSM drafted the manuscript and made substantial contributions to acquisition, experimental work, analysis and interpretation of data; FY and MSJ designed the study and were responsible for the revision of the manuscript; SK provided experimental guidance. All authors read and approved the final manuscript.

\section{Authors' information}

Safa Senan Mahmod finished her Masters degree in March 2015 in Biotechnology Engineering at the International Islamic University Malaysia under supervision of Prof. Faridah Yusof. Her research was on the co-immobilization of multi-purpose biocatalyst using cross-linked enzyme aggregates multiCLEA. Currently, Safa is a PhD candidate in Chemical Engineering at the National University of Malaysia.

Professor Dr. Faridah Yusof started her career as a lecturer at the Department of Chemistry, UTM, Kuala Lumpur in 1983. In 1988, she joined the Rubber Research Institute of Malaysia (RRIM) as a Research Officer working as a Biochemist. Prof Faridah's Ph.D. research was on the proteinaceous factors that have purported roles in the biosynthesis of rubber molecules in latex. In 2004, she joined the Department of Biotechnology Engineering IIUM, as an Associate Professor. Her main area of research includes biotransformation, bioprocess and bioseparation engineering, purification technology, protein/ peptides research, enzyme technology, latex biochemistry and natural rubber/carbon nanotubes nanocomposites. She has authored and co-authored papers and written book chapters in her areas of interests. In 2006, Prof Faridah was appointed the Deputy Dean of the Research Management Centre, IIUM, handling the Research and Innovation Unit.

Associate Professor Dr. Mohammed Saedi Jami, an Ethiopian national is a Chemical Engineer and lecturer in Department of Biotechnology Engineering, Faculty of Engineering, International Islamic University Malaysia (IIUM). He earned BSC in Chemical Engineering from Addis Ababa University, Ethiopia, MSc and PhD in Chemical Engineering from Nagoya University, Japan, postdoctoral researcher (JSPS) at Suzuka National College, Japan. He is member of The Filtration Society Japan, Malaysian Water Association and Malaysian
Society for Engineering and Technology. His areas of expertise are water and wastewater treatment (municipal and industrial), Environmental Engineering, Artificial Neural Network Modeling of environmental systems, Membrane Processes, Bioseparation Processes, Immobilization, Transport Phenomena. He has authored and co-authored over 170 publications in book chapters, journals, conferences, etc.

Soofia Khanahmadi was born in Iran, in 1987. She received her degree in Cellular and Molecular Biology, Microbiology in 2010 in Iran. In 2015, she obtained a master's degree in Biochemical and Biotechnology Engineering at the International Islamic University Malaysia, under supervision of Prof. Dr. Faridah Yusof. Her master research was on Immobilization of lipase from cocoa pod husk with cross-linked enzyme aggregate technology to be utilized in biodiesel production reaction.

\section{Acknowledgements}

The authors are grateful to the Department of Biotechnology Engineering of the International Islamic University Malaysia (IIUM) for providing the laboratory facilities.

\section{Competing interests}

The authors declare that they have no competing interests.

Received: 27 September 2015 Accepted: 27 December 2015

Published online: 11 January 2016

\section{References}

Aytar BS, Bakir U (2008) Preparation of cross-linked tyrosinase aggregates. Process Biochem 43:125-131

Barbosa O, Ortiz C, Berenguer-Murcia A, Torres R, Rodrigues RC, FernandezLafuente R (2014) Glutaraldehyde in bio-catalysts design: a useful crosslinker and a versatile tool in enzyme immobilization. R Soc Chem Adv. 4:1583

Bradford MM (1976) A rapid and sensitive method for the quantitation of microgram quantities of protein utilizing the principle of protein-dye binding. Anal Biochem 72:248-254

Brady D, Jordaan J (2009) Advances in enzyme immobilization. Biotechnol Lett 31:1639-1650

Cabana H, Jones JP, Agathos SN (2007) Preparation and characterization of cross-linked laccase aggregates and their application to the elimination of endocrine disrupting chemicals. J Biotechnol 132:23-31

Cao L, Schmid RD (2005) Carrier-bound immobilized enzymes: principles, application and design. Wiley-VCH Verlag GmbH and Co, Weinheim

Capiralla H, Hiroi T, Hirokawa T, Maeda S (2002) Purification and characterization of a hydrophobic amino acid-specific endopeptidase from Halobacteriumhalobium $\mathrm{S} 9$ with potential application in debittering of protein hydrolysates. Process Biochem 38:571-579

Cruz J, Barbosa O, Rodrigues RC, Fernandez-Lafuente R, Torres R, Ortiz C (2012) Optimized preparation of CALB-CLEAs by response surface methodology: the necessity to employ a feeder to have an effective crosslinking. $J$ Mol Catal B Enzym 80:7-14

Cui JD, Cui LL, Zhang SP, Zhang YF, Su ZG, Ma GH (2014) Hybrid magnetic cross-linked enzyme aggregates of phenylalanine ammonia lyase from Rhodotorulag/utinis. Pubmed PloS One. 9(5):e97221

Dong T, Zhao L, Huang Y, Tan X (2010) Preparation of cross-linked aggregates of aminoacylase from Aspergillusmelleus by using bovine serum albumin as an inert additive. Biores Technol 101:6569-6571

Garcia-Galan C, Berenguer-Murcia A, Fernandez-Lafuente R, Rodrigues RC (2011) Potential of different enzyme immobilization strategies to improve enzyme performance. Adv Synth Catal 353:2885-2904

Gupta R, Beg Q, Lorenz P (2002) Bacterial alkaline proteases: molecular approaches and industrial applications. Appl Microbiol Biotechnol 59(1):15-32

Gupta P, Dutt K, Misra S, Raghuwanshi S, Saxena RK (2009) Characterization of cross-linked immobilized lipase from thermophilic mould Thermomyces lanuginosa using glutaraldehyde. Biores Technol 100:4074-4076

Hormigo D, García-Hidalgo J, Acebal C, Mata I, Arroyo M (2012) Preparation and characterization of cross-linked enzyme aggregates (CLEAs) of recombinant poly-3-hydroxybutyrate depolymerase from Streptomyces exfoliates. Biores Technol 115:177-182 
JMP (2005) Design of experiments, release 6. SAS Institute Inc., Cary Kartal F, Janssenb MHA, Hollmannc F, Sheldon RA, Kılınc A (2011) Improved esterification activity of Candida rugosa lipase in organic solvent by immobilization as cross-linked enzyme aggregates (CLEAs). J Mol Catal B Enzym 71:85-89

Khanahmadi S, Yusof F, Amid A, Mahmod SS, Mahat MK (2015) Optimized preparation and characterization of CLEA-lipase from cocoa pod husk. J Biotechnol 202:153-161

Kim MH, Parka S, Kim YH, Won K, Lee SH (2013) Immobilization of formate dehydrogenase from Candida boidiniithrough cross-linked enzyme aggregates. J Mol Catal B Enzym 97:209-214

Lei Z, Bi S (2007) The silica-coated chitosan particle from a layer-bylayer approach for pectinase immobilization. Enzym Micro Technol 40:1442-1447

Li S, He B, Bai Z, Ouyang P (2009) A novel organic solvent-stable alkaline protease from organic solvent-tolerant Bacillus licheniformis YP1A. J Mol Catal B Enzym 56(2-3):85-88

Mahmod SS, Yusof F, Jami MS (2014) Extraction and screening of various hydrolases from Malaysian channel catfish (Ictalurus punctatus) viscera. Int J Chem Environ Eng 2(5):79-82

Maldonado-Valderrama J, Patino MR (2010) Interfacial rheology of protein-surfactant mixtures. Curr Opin Colloid Interface Sci 15:271-282

Matijošyte I, Arends IWCE, de Vries S, Sheldon RA (2010) Preparation and use of cross-linked enzyme aggregates (CLEAs) of laccases. J Mol Catal B Enzym 62(2):142-148

Mogensen JE, Kleinschmid JH, Schmidt MA, Otzen DE (2005) Misfolding of a bacterial autotransporter. Protein Sci 14(11):2814-2827

Nelson DL, Cox MM (2004) Lehninger principles of biochemistry. W. H. Freeman, New York, pp 47-75

Pan J, Dang N-D, Zheng G-W, Cheng B, Ye Q, Xu J-H (2014) Efficient production of I-menthol in a two-phase system with SDS using an immobilized Bacillus subtilis esterase. Biores Bioprocess 1:12

Parmar A, Kumar H, Marwaha S, Kennedy JF (2000) Advances in enzymatic transformation of penicillins to 6-aminopenicillanic acid (6-APA). Biotechnol Adv 18(4):289-301

Rehman HU, Aman A, Silipo A, Qader SAU, Molinaro A, Ansar A (2013) Degradation of complex carbohydrate: immobilization of pectinase from Bacillus licheniformis KIBGE-IB21 using calcium alginate as a support. Food Chem 139:1081-1086

Ribeiro MHL, Rabaça M (2011) Cross-linked enzyme aggregates of naringinase: novel biocatalysts for naringin hydrolysis. Enzyme Res 2011:8 (Article ID 851272)

Sangeetha K, Abraham TE (2008) Preparation and characterization of crosslinked enzyme aggregates (CLEA) of subtilisin for controlled release applications. Int J Biol Macromol 43:314-319

Schoevaart R, Wolbers MW, Golubovic M, Ottens M, Kieboom APG, van Rantwijk F, van der Wielen LAM, Sheldon RA (2004) Preparation, optimization, and structures of cross-linked enzyme aggregates (CLEAs). Biotechnol Bioeng 87(6):754-762

Serdakowski AL, Dordick JS (2008) Enzyme activation for organic solvents made easy. Trend Biotechnol. 26:48-54

Shah S, Sharma A, Gupta MN (2006) Preparation of cross-linked enzyme aggregates by using bovine serum albumin as a proteic feeder. Anal Biochem 351:207-213

Sheldon R (2007) Enzyme immobilization: the quest optimum performance review. Adv Synth Catal 349:1289-1307

Sheldon RA, Schoevaart R, Langen LM (2005) Cross-linked enzyme aggregates (CLEAs): a novel and versatile method for enzyme immobilization. Biocatal Biotransform 23:141-147
Sigma-Aldrich (2013) Universal protease activity assay: casein as a substrate. http://www.sigmaaldrich.com/life-science/learning-center/life-sciencevideo/universal-protease.html

Singh RK, Tiwari MK, Singh R, Lee J-K (2013) From protein engineering to immobilization: promising strategies for the upgrade of industrial enzymes. Int J Mol Sci 14:1232-1277

Skovgaard J, Bak CA, Snabe T, Sutherland DS, Laursen BS, Kragh KM, Besenbacher F, Poulsen CH, Shipovskov S (2010) Implementation of crosslinked enzyme aggregates of proteases for marine paint applications. J Mater Chem 2010(20):7626-7629

Soares VF, Castilho LR, Bon EP, Freire DM (2005) High-yield Bacillus subtilis protease production by solid-state fermentation. Appl Biochem Biotechnol 121:311-319

Tang XM, Lakay FM, Shen W, Shao W, Fang H, Prior BA, Wang Z, Zhuge J (2004) Purification and characterization of an alkaline protease used in tannery industry from Bacillus licheniformis. Biotechnol Lett 26:1421-1424

Torabizadeh H, Tavakolib M, Safari M (2014) Immobilization of thermostable a-amylase from Bacillus licheniformisby cross-linked enzyme aggregates method using calcium and sodium ions as additives. J Mol Catal B Enzym 108:13-20

Torres MPG, Foresti ML, Ferreiraa MI (2013) Effect of different parameters on the hydrolytic activity of cross-linked enzyme aggregates (CLEAs) of lipase from Thermomyces lanuginose. Biochem Eng J 72:18-23

Tutar H, Yilmaza E, Pehlivan E, Yilmaz M (2009) Immobilization of Candida rugosa lipase on sporopollenin from Lycopodium clavatum. Int J Biol Macromol 45:315-320

Wang M, Qi W, Jia C, Ren Y, Su R, He Z (2011) Enhancement of activity of cross-linked enzyme aggregates by a sugar-assisted precipitation strategy: technical development and molecular mechanism. J Biotechnol 156:30-38

Xu DY, Yang Z (2013) Cross-linked tyrosinase aggregates for elimination of phenolic compounds from wastewater. Chemosphere 92:391-398

Yildirim D, Tükel SS, Alagöz D (2014) Crosslinked enzyme aggregates of hydroxynitrilelyase partially purified from Prunusdulcis seeds and its application for the synthesis of enantiopure cyanohydrins. Biotechnol Prog 30(4):818-827

Yu HW, Chen H, Wang X, Yang YY, Ching CB (2006) Cross-linked enzyme aggregates (CLEAs) with controlled particles: application to Candida Rugosa lipase. J Mol Catal B Enzym 43:124-127

Yu CY, Li XF, Loub WY, Zong MH (2013) Cross-linked enzyme aggregates of Mung bean epoxide hydrolases: a highly active, stable and recyclable biocatalyst for asymmetric hydrolysis of epoxides. J Biotechnol 166:12-19

Yusof F, Firdaus MR, Jimat DN (2013) Preparation of cross-linked enzyme aggregate (CLEA)-lipase from skim latex serum of HeveaBrasiliensis. ICBioE2013, Kuala Lumpur, pp 2-4

Zhou J (2009) Immobilization of alliinase and its application: flow-injection enzymatic analysis for alliin. Afr J Biotechnol 8(7):1337-1342

Zhu K, Jutila A, Tuominen EKJ, Patkar SA, Svendsen A, Kinnunen PK (2001) Impact of the tryptophan residues of Humicolalanuginosa lipase on its thermal stability. J Biochim Biophys Acta 1547:329-338

\section{Submit your manuscript to a SpringerOpen ${ }^{\odot}$ journal and benefit from:}

- Convenient online submission

- Rigorous peer review

- Immediate publication on acceptance

- Open access: articles freely available online

- High visibility within the field

- Retaining the copyright to your article

Submit your next manuscript at $>$ springeropen.com 